\title{
Trombólise Mecânica na Trombose Venosa Profunda: Quando e como Indicar
}

\author{
Pinto DM. ${ }^{1}$ \\ ${ }^{1}$ Belo Horizonte - Brasil. \\ E-mail:dmendes@gmail.com
}

Pinto, D.M. 2013. Trombólise Mecânica na Trombose Venosa Profunda: Quando e como Indicar, p.77. In: Bastos, Francisco Reis. Anais do V Simpósio Internacional de Flebologia [Blucher Medical Proceedings n.1 v.1]. São Paulo:

Blucher, 2014

http://dx.doi.org/10.5151/medpro-flebo-SIF_50
O tratamento da TVP com anticoagulantes é bem estabelecido há décadas. Porém, nos casos de trombose venosa proximal, o uso isolado da heparina leva a alta incidência de síndrome pós-trombótica (SPT). Vários estudos mostram que a incidência de SPT na TVP proximal ocorre em 20 a 70\%. A retirada percutânea de trombos reduz a incidência de SPT após a trombose de veias do sistema ilíaco-cava. A retirada percutânea é feita por trombólise química com cateter associada ou não à trombólise mecânica (aspiração dos trombos). A vantagem da trombólise mecânica é a rápida desobstrução do membro acometido, importante em casos de flegmasia cerulea. A aspiração percutânea proporciona a redução da dose do trombolítico a ser usado, uma vez que o volume maior de trombos foi retirado. São duas as desvantagens da trombectomia mecânica: hemólise intravascular e embolia pulmonar. Portanto, o procedimento deve ser feito somente em pacientes jovens e que se beneficiam da rápida retirada de trombos no sistema venoso ilíaco-cava.

Palavras chave: trombose venosa profunda, trombectomia, trombolítico, trombofilia. 